\title{
Direct Democracy, Postal Voting, and the Composition of Turnout
}

December 9, 2016

Word count: 8,915

Existing work on the effects of electoral reforms suggests that decreasing the costs of voting may exacerbate rather than reduce representational biases in turnout. We argue that some electoral institutions may have more uniform mobilization effects than previously thought and exploit the sequential introduction of postal voting in Switzerland to analyze how an exogenous decrease in voting costs affects the political and socio-demographic composition of turnout in direct legislation. In contrast to previous studies we find that postal voting mobilizes equally along many dimensions including individuals' political knowledge, employment status, and religious denomination. Although it does mostly activate supporters of leftist and centrist parties, less politically interested individuals, and high earners, these changes have only limited effects on the overall turnout composition and are unlikely to affect referendum outcomes. Our results alleviate some of the concerns about the negative side effects of electoral reforms on political choice in large electorates. 


\section{Introduction}

Only those who cast a ballot determine the outcome of an election. Yet virtually all democracies exhibit a degree of unequal political participation. The old, the more educated, and the wealthy have higher probabilities to vote than the young, the less educated, and the poor (Fujiwara 2015; Nevitte, Blais, Gidengril and Nadeau 2009; Leighley and Nagler 2007). This representational inequality may lead to biases in public policy because policymakers are most responsive to the needs of those who are politically active (Lijphart 1997; Butler 2014). Moreover, many worry that low turnout prepares the ground for affluent special interests covertly influencing the policymaking process, often to the detriment of the public good (Bolling 1986). As a consequence, some expect that high levels of turnout would lead to decisive shifts in public policy, or, as President Obama puts it: "It would be transformative if everybody voted - that would counteract money more than anything." 1

To increase political participation, scholars and pundits frequently advocate electoral reforms that reduce the costs of voting. Among the set of potential policy instruments, postal voting stands out as a particularly attractive way of facilitating participation of those who would abstain otherwise by offering citizens more flexibility in deciding when and where to vote. Yet electoral reforms that make it less costly to vote may also have negative effects in terms of both the efficiency and quality of electoral choice. First, to the extent that postal voting fails to alter election outcomes, lower turnout may actually be more economically efficient. Second, if postal voting mobilizes especially those with low levels of political knowledge, this could lead to qualitatively inferior, more volatile, and more extreme electoral choices, which, in turn, could reduce policy stability and the ability of democracies to pursue long-term policy goals.

Although postal voting seems increasingly popular among pundits and policymakers to counteract growing voter fatigue and representational inequality, the available evidence sug-

\footnotetext{
${ }^{1}$ CNN Politics, "Obama: Maybe it's time for mandatory voting",http://edition.cnn.com/2015/03/ 19/politics/obama-mandatory-voting/.
} 
gests that this reform fails to reduce biases in turnout. Instead, the most widely cited studies (Southwell and Burchett 1997; Southwell and Burchett 2001) find that in a 1996 special Senate election in the state of Oregon additional voters mobilized by the opportunity to vote by mail were more educated and better informed about politics. Berinsky, Burns and Traugott (2001) show that voting-by-mail is associated with a decrease in the long-term probability of voting among individuals that already have been non-voters in the past. Subsequent studies have examined whether postal voting mobilizes citizens with specific political ideologies in American presidential (Gomez, Hansford and Krause 2007) and congressional elections (Citrin, Schickler and Sides 2003) or increases the share of less educated individuals voting on ballot propositions (Hodler, Luechinger and Stutzer 2015; Fujiwara 2015). The knowledge generated by these more recent studies still seems consistent with Berinsky's (2005) summary of earlier work which concludes that "[...] voting reforms do not correct the biases inherent in the electorate, and in some cases, reforms may even worsen these biases" (p. 482).

While these previous studies have generated important knowledge about the consequences of electoral reform in specific states and elections, we still lack evidence on how electoral institutions affect turnout in referendums in which citizens decide directly on specific policy proposals. This lack of knowledge is regrettable since the ability to vote directly over welldefined policy issues - as opposed to choosing between complex policy and valence bundles offered by parties or candidates - provides citizens with a particularly powerful instrument to shape public policy. Moreover, and abstracting away from replicability problems that seem to exist with some of the earlier findings (Gronke and Miller 2012), previous work has neither examined in detail how changes in individuals' voting probabilities shift the sociodemographic and political composition of turnout when compared with the voting-eligible population, nor has it assessed whether electoral reform may be consequential for referendum outcomes. Although this more encompassing assessment of the effects of electoral reforms seems important, the estimations necessary for such a detailed analysis require data sets that 
are much larger than those employed by earlier work: They would have to cover longer time periods (in which citizens could possibly vote on hundreds of referendums) and a large set of individuals - a type of big data that was unavailable to previous studies.

We address these shortcomings by studying the long-term effects of postal voting on turnout in direct legislation in Switzerland (1981-2009). In contrast to electoral reforms that explicitly condition on socio-demographic characteristics such as female suffrage or literacy tests, postal voting does not obviously imply differential effects that directly relate to characteristics such as an individual's gender, age, or religious orientation. Yet, postal voting may still have heterogeneous mobilization effects (Berinsky, Burns and Traugott 2001). First, as previous studies have argued (Gomez, Hansford and Krause 2007; Tucker, Vedlitz and DeNardo 1986), to the extent that individuals' propensities to vote correlate with their political and ideological preferences, even a non-discriminatory get-out-the-vote instrument such as postal voting can benefit specific parties or ideological platforms. Second, the availability of voting by mail may reduce the costs of voting more strongly for those with low levels of political interest as these individuals generally derive less utility from casting a ballot and therefore tend to abstain more frequently. Third, postal voting should increase turnout more strongly among high-income individuals because they face higher opportunity costs (arising from going to the voting both and potentially waiting to vote) than low earners. Finally, the option of voting by mail should increase political participation mostly among those with low and medium levels of education because political choices in referendums require evaluating and choosing between complex policy proposals. Since the costs of turning out comprise these evaluation and decisionmaking costs as well as the costs of going to the voting booth and waiting to vote, postal voting will be more likely to shift the net costs of voting below the critical threshold that will make even those with lower levels of education participate in referendums.

To evaluate these predictions, we exploit the sequential introduction of postal voting in Swiss cantons as a natural experiment and combine large individual-level and aggregate 
level data to provide unusually detailed insights into how the introduction of postal voting changes the composition of turnout in referendums. This allows us to estimate both its aggregate effect on turnout and, for the first time, decompose this effect into its sociodemographic and political individual-level fragments. Based on an analysis of all 239 Swiss referendums from 1981 to 2009 in combination with detailed survey data from over 79,000 individuals we subsequently simulate the consequences of postal voting on direct-democratic policy decisions.

We leverage large amounts of individual-level data to provide a more detailed picture of how postal voting affects the composition of turnout and compare these effects against the benchmark distribution of citizens in the population. Our estimates suggest that the positive effect of postal voting on turnout results from a largely equal increase in participation across ideological orientations, political knowledge, trust in government, employment status, religious denomination, as well as age and gender groups. However, we find that postal voting significantly increases participation of individuals with low levels of interest in politics, high earners, and citizens with low and medium levels of education.

While interesting, these estimates alone remain insufficient to fully assess the consequences of electoral reforms. As we document in the theory part, evaluating the effects of electoral reform requires a comparison with the benchmark distribution observable in the population of voting-eligible individuals. This is because, irrespective of whether the estimated marginal effects are large or small, they may improve or worsen biases in turnout depending on the benchmark composition and the pre-reform turnout propensities of different political and socio-demographic groups. Therefore, we not only decompose the turnout increase of postal voting, but also map in detail the composition of turnout with and without postal voting and compare this distribution with the composition of all eligible voters. In addition, we offer simulation results suggesting that postal voting does not lead to decisive shifts in referendum results.

This study makes theoretical, empirical, and policy contributions. First, we develop and 
evaluate theoretical arguments about how different subgroups of the electorate respond to the introduction of postal voting in referendums. Second, by analyzing the detailed shifts in the composition of turnout that result from the availability of postal voting for a large set of referendums, our results promise to shed light on whether an electoral reform can succeed in activating passive constituencies more generally (Nichter 2008). Third, our findings inform the debate about the unintended consequences of electoral reforms in light of their likely policy consequences. We elaborate on these implications in the conclusion.

\section{Cost Sensitivities, Turnout, and Postal Voting}

Turnout constitutes an aggregate phenomenon that results from citizens' individual decisions to participate in an election, which, in turn, depends on the expected costs and benefits of voting (Downs 1957; Riker and Ordeshook 1968). A large literature has examined how changes in the costs of voting affects turnout using observational, field-experimental, as well as lab-experimental data (see Feddersen (2004) for a review). For example, turnout responds to factors such as bad weather (Tucker, Vedlitz and DeNardo 1986; Gomez, Hansford and Krause 2007; Fraga 2011), natural disasters (Sinclair, Hall and Alvarez 2011; Gasper and Reeves 2011; Bechtel and Hainmueller 2011), the removal or relocation of polling stations (McNulty, Dowling and Ariotti 2009; Brady and McNulty 2011; Gibson, Bonggeun, Stillman and Boe-Gibson 2012), the availability of electronic voting (Fujiwara 2015) and exit poll information (Morton, Muller, Page and Torgler 2015), and compulsory voting laws (Jackman 1987; Panagopoulos 2008; Bechtel, Hangartner and Schmid 2015). The theoretical models that underlie these empirical contributions typically follow Downs (1957) by assuming that citizens have homogeneous voting costs or, alternatively, by focusing on a representative actor characterized by a specific cost level as is the case in the first generation of formal voting models (Riker and Ordeshook 1968; Palfrey and Rosenthal 1983).

A growing literature has moved towards more realism by allowing individuals to have 
different voting costs (Ledyard 1984; Palfrey and Rosenthal 1985; Levine and Palfrey 2007). These models predict heterogeneous effects of cost shocks that depend on where an individual is located in the cost distribution. Although an individual's voting cost remains an ultimately unobservable characteristic, these models have an important, empirically observable implication: A change in the costs of voting may have distinct effects on different parts of the citizenry. The empirical literature supports this idea. For example, relocating polling stations reduces turnout most strongly among older individuals (Brady and McNulty 2011). Recently, Panagopoulos and Abrajano (2014) re-analyze the field-experimental data from Gerber, Green and Larimer (2008) and conclude that social pressure is most effective in stimulating turnout among the elderly.

The most politically contentious effects of changes in the costs of voting arise because differential mobilization may have an important impact on electoral and policy outcomes. For example, Gomez, Hansford and Krause (2007) find that bad weather depresses turnout more strongly among those that identify with the Democrats. As a consequence, the Republican party receives more votes on rainy election days than it would have received if the weather had been nice. Depending on the partisan margin, this type of differential mobilization may have notable effects on the distribution of political power. In his study of compulsory voting in Australia, Fowler (2013) documents that making it mandatory to vote increases the Labor Party's vote shares by 7 to 10 percentage points and Fujiwara (2015) finds that the availability of electronic voting mainly mobilizes less educated individuals which, in turn, translates into higher health care spending. These studies suggest that the differential mobilization effects of electoral reforms may have substantial consequences for public policy choices.

Theoretically, and in contrast to, for example, the removal of literacy tests (Filer, Kenny and Morton 1993), the introduction of female suffrage (Husted and Kenny 1997), or the availability of electronic voting (Fujiwara 2015), postal voting does not impose obvious differential costs that one would expect to vary across socio-demographic groups. In this sense, 
the availability of voting by mail constitutes an exogenous decrease in the costs of participating in elections as it merely offers citizens more freedom to decide when and where to vote. Consequently, we expect postal voting to increase turnout across many socio-demographic subgroups of the adult population. However, policy interventions whose effects on subgroups of the population have the same (positive) direction may still have heterogeneous effects on civic engagement in that their impact differs significantly in terms of magnitude. Moreover, even with homogeneous mobilization effects assessing the impact of electoral reforms on representational inequality and, in turn, public policy outcomes, requires a comparison that takes into account both the composition of the voting-eligible population and the voting propensities of different societal subgroups. We first develop the theoretical arguments on the heterogeneous effects of postal voting and then analyze how we can assess the representational consequences of electoral reforms more generally.

\section{Postal Voting and Differential Mobilization}

How can changes in the costs of voting affect election results? In an influential study of turnout in presidential elections, Gomez, Hansford and Krause (2007) argue that rainfall increases the Republican party's vote share because the set of potential voters consists of two subsets (Tucker, Vedlitz and DeNardo 1986). The first set comprises citizens that almost always turn out ("likely voters") while the second set consists of individuals that have a much lower propensity to participate in political collective action ("less likely voters"). Since the later group comprises more Democrats, the Democratic party receives higher vote shares in elections with high turnout levels than in comparable low-turnout elections.

This logic may have the potential to generalize to other contexts and electoral institutions. In the Swiss political system, for example, individuals with a lower propensity to vote tend to identify with leftist parties such as the Socialist Party (SP) and centrist parties such as the Christian Democratic People's Party (CVP) or the Liberals (FDP). In contrast, likely voters typically identify with moderate or rightist parties such as the Swiss People's Party 
(SVP). Consequently, when examining the partisan composition of turnout, we would expect that postal voting will have a relatively stronger effect on supporters of leftist and centrist parties.

Hypothesis 1 (Partisan Identification) The positive effect of postal voting on turnout is stronger among supporters of leftist parties.

An alternative way of conceptualizing citizens' political orientations draws on their positions on the ideological left-right dimension. Analogously to the theoretical argument underlying Hypothesis 1, one would expect that those located on the left and in the center of the ideological spectrum should respond more strongly to the availability of postal voting than those holding rightist ideological orientations.

Hypothesis 2 (Ideology) The positive effect of postal voting on turnout is stronger among ideologically left individuals than among those located in the middle or on the left of the ideological spectrum.

Citizens not only differ with respect to their partisan and ideological preferences, but also in the attention paid to political matters which is a precondition for making informed decisions when voting on ballot propositions (Bowler and Donovan 2000; Magleby 1984). While some share a strong interest in politics, others remain largely inattentive. An individual's political interest tends to strongly predict civic engagement (Verba, Schlozman and Brady 1995) as it reduces the costs of collecting and processing information required for forming a consistent opinion on an issue (Zaller 1992). Consequently, variation in individuals' political interest may give rise to different responses to the introduction of postal voting. Individuals with low levels of political interest generally derive less utility from casting a ballot and therefore tend to abstain. Postal voting decreases the costs of casting a ballot which compensates for the lower utility these individuals derive from participating in a political activity because they pay little attention to political matters. This shifts the costs 
of voting below the critical value, and therefore, also individuals with less political interest participate. As a consequence, and in line with Hodler, Luechinger and Stutzer (2015), we expect that the mobilizing effect of postal voting should be more pronounced among those with low levels of political interest:

Hypothesis 3 (Political Interest) The positive effect of postal voting on turnout is stronger among the less politically interested than among the politically interested.

Citizens generally seem poorly informed about political issues as they fail to correctly answer seemingly trivial questions about politics (Lupia and McCubbins 1998) and this finding seems to generalize to voting on ballot proposition (Magleby 1984; Bowler and Donovan 2000). Yet, some individuals possess relatively less political knowledge than others and this affects their costs of civic engagement (Galston 2001). The less knowledgeable find it more difficult to form a consistent opinion on an issueand lack the resources necessary to draw on elite cues (Zaller 1992) that they could use to compensate for the unavailability of encyclopedic information (Lupia 1992). Therefore, one would expect that the less knowledgeable benefit more from the availability of postal voting than those with higher levels of political knowledge because the later group already has a relatively high propensity to vote.

Hypothesis 4 (Political Knowledge) The positive effect of postal voting on turnout is stronger among the less politically knowledgeable than among those with more political knowledge.

Another characteristic that could affect how individuals react to the availability of postal voting is one's level of education. Typically, education is viewed as a resource that provides information about "the ability to bear the costs of different types of participation" (Verba, Schlozman and Brady 2000, 254). The more educated possess cognitive skills and knowledge that facilitate opinion formation and thereby reduce the costs of political choice (Nevitte et al. 2009; Verba, Schlozman and Brady 1995). This appears particularly important in our 
context because political choices in referendums require evaluating and choosing between complex policy proposals. Since the costs of turning out comprise these evaluation and decisionmaking costs as well as the costs of going to the voting booth and waiting to vote, postal voting should have particularly strong effects on those with lower levels of formal education.

Hypothesis 5 (Education) The positive effect of postal voting on turnout is stronger among those with low/medium levels of income than among those with high levels of education.

Finally, heterogeneity in the effect of postal voting may originate from individual differences in income levels. Typically, low earners have a lower propensity to vote because they are more concerned about securing an income that allows them to meet their own basic needs and those of their families than about participating in political decisionmaking processes (Nevitte et al. 2009). At first glance, this would suggest that reducing the costs of voting by introducing postal voting has the potential to increase participation among those with low income more strongly than among high earners. Yet an opportunity cost perspective leads to a different theoretical expectation: High-income individuals face higher opportunity costs that arise from going to the polling station and waiting to vote than low earners. This argument predicts that postal voting should have a stronger mobilization effect among those with higher income levels.

Hypothesis 6 (Income) The positive effect of postal voting on turnout is stronger among those with higher income than among those with lower incomes.

\section{Electoral Reform and the Composition of Turnout}

Even if an electoral reform such as the introduction of postal voting has equal mobilization effects across socio-demographic subgroups, this may still affect the outcomes of policy 
choices because the turnout probabilities of these subgroups vary. Therefore, constant mobilization effects may lead to differential changes in the socio-demographic composition of turnout. For illustrative purposes, assume there is an equal share of female and male citizens in the population. Suppose that without postal voting, turnout among female individuals is $20 \%$ and turnout among male citizens is $90 \%$. This implies that the share of men in the gender composition of turnout is $\frac{0.5 \times 0.9}{0.5 \times 0.9+0.5 \times 0.2}=81 \%$ and the turnout share of women is $19 \%=1-0.81$. If postal voting uniformly increases the probability of voting, say, by 5 percentage points, this means that under postal voting, the share of male voters equals $79 \%=\frac{.5 \times .95}{.5 \times .95+.5 \times .25}$ and, consequently, the share of female voters is $21 \%$. Thus, postal voting has decreased the share of male voters in the gender composition of turnout by 2 percentage points $(-.02=.79-.81)$ while the share of female voters has increased by 2 percentage points. This differential total effect - despite a homogeneous treatment effect - underscores the importance of estimating the impact of policy instruments that aim to increase political participation on the composition of turnout even if the mobilization effects themselves are homogeneous across subsets of the population. Otherwise, it will not be possible to fully gauge the impact of electoral reforms on representational inequality and public policy.

In the following we explore these predictions using individual and aggregate level data from Switzerland. We exploit the sequential introduction of postal voting to estimate the total mobilization effect of postal voting (i), explore the heterogeneity of the effect of postal voting by socio-demographic and political subgroups, compute the impact of the estimated effects on the composition of turnout (iii), and provide point predictions for referendum outcomes to gauge the policy relevance of postal voting in the context of direct legislation. 


\section{Background and Data}

\section{Institutional Context: Direct Democracy in Switzerland}

The Swiss political system offers several direct-democratic instruments that can be classified into two types. The first type offers the possibility of preventing policies that change the status quo. This type comprises the mandatory and the optional referendum. All federal level constitutional amendments and international treaties (since 1977) have to be put to a mandatory referendum. Moreover, using the so called optional referendum, citizens can challenge all federal bills passed by the Swiss parliament and put them to a vote conditional on having met the signature requirements. ${ }^{2}$ The second type of direct-democratic instruments consists of the popular initiative which allows citizens to initiate direct legislation, i.e. to change the status quo. ${ }^{3}$

The use of direct democratic instruments has increased strongly in the past decades. Between 1848 and 1949, the Swiss voted only on about 1 to 2 ballot propositions per year. In the second half of the 20th century, this number increased to 7 proposals per year. In our sample period (1981-2009), Swiss citizens voted on 8 proposals per year on average. We note that apart from the sequential introduction of postal voting, there were no other major changes to Swiss electoral institutions that should have affected canton-level turnout differentially. This is because the introduction of female suffrage at the federal level occurred in 1971 and our data does not start until 1981. Although the voting age was reduced from 20 to 18 years in 1991, i.e. within the period we analyze, this will not confound our results because the policy was introduced at the federal level and therefore affected all cantons simultaneously.

Why did Switzerland introduce postal voting? After World War II, the country experienced a steady decline in turnout. ${ }^{4}$ To counteract this trend and respond to demands for

\footnotetext{
${ }^{2}$ The number of signatures needed to qualify a measure for a referendum is 50,000 .

${ }^{3}$ Launching a popular initiative requires 1000,000 collected signatures.

${ }^{4}$ Turnout in federal referendums in the $1920-49$ period was $61.4 \%$ and decreased to $50.8 \%$ in the $1950-59$ period. Turnout in federal elections decreased from $75.7 \%$ to $69.9 \%$.
} 
more convenient forms of voting (Biggers and Hanmer 2015), the cantons of Switzerland began to sequentially introduce postal voting over an almost thirty years period, starting in 1978 with Basel-Landschaft and ending with Ticino in 2005. The introduction took place in two phases (see Table 2 in the Appendix). In the first phase, postal voting remained limited to citizens that were unable to vote in person by going to a polling station for health-related or important professional reasons (Luechinger, Rosinger and Stutzer 2007, 171). In the second phase, all citizens were allowed to vote by mail. Swiss authorities implemented a very convenient version of postal voting by automatically mailing each citizen a ballot that could either be used to vote in person at the polling station or mailed back. Following Luechinger, Rosinger and Stutzer (2007), we focus on the introduction of unconditional postal voting for all citizens because of two reasons. First, the set of individuals eligible to vote by mail under the initial form of postal vote remained negligibly small compared to the overall size of the citizenry. Second, even those that in principle qualified for postal voting still had to specifically request it, which imposed substantial costs that strongly reduced its usage.

\section{Data}

Our canton-level referendum data come from the Swiss Federal Statistical Office and covers all direct democratic decisions from 1981 to 2009. This includes both salient foreign pol-

icy decisions, such as the referendum on Switzerland's membership in the United Nations (1986, 2003), participation in the European Economic Area (1992), and the various bilateral agreements with the European Union $(2000,2005)$ and important domestic policy choices, including several referendums on the welfare state (1993, 2004, 2008), immigration (1988, 1996, 2000), and the protection of gay rights (2005). Turnout in referendums varies substantially from $42.1 \%$ on 9 February 2003, when Swiss citizens voted on a bill on the revision of political rights and on a proposal about hospital finances, to 89.2\% on 6 December 1992 when the membership to the European Economic Area was rejected.

Our individual-level data draws on the VOX telephone surveys which are conducted 
directly after each federal referendum on a representative sample of the adult population (FORS 2012). In total, our data comprises 79,041 respondents that considered 239 proposals on 81 referendum days in the period 1981-2009. ${ }^{5}$ The covariate information includes reported turnout, vote choice, as well as socio-demographic and political variables such as political ideology, party affiliation, political interest, political knowledge, trust in government, age, education, employment status, income, native language, and residence. The appendix provides detailed information about the coding and measurement of these variables.

\section{The Mobilization Effect of Postal Voting}

We first estimate the average mobilization effect of postal voting using a difference-indifferences design. We then break down this effect into its components. Before turning to our difference-in-differences estimates, we discuss the plausibility of the parallel trends assumption, a key identification assumption that underlies our research design.

\section{Parallel Trends Assumption: Placebo Tests}

We employ a generalized difference-in-differences design to estimate the average mobilization effect of postal voting. The credibility of this research design in identifying a causal effect relies on the parallel trends assumption. This assumption requires that turnout in the cantons that introduced postal voting would have evolved similarly to turnout in the cantons that had not (yet) introduce postal voting. Although this assumption can not be evaluated directly since it involves a counterfactual outcome that remains unobserved, we can assess its plausibility by exploring trends in turnout prior to the availability of postal voting. This placebo test is typically implemented by comparing trends in the outcome variable one period before the intervention. Since we have a much longer time series, we are able to assess the plausibility of the parallel trends assumption over a larger set of pre-treatment periods. This

\footnotetext{
${ }^{5}$ The sample sizes vary between 670 and 6,042 respondents per referendum day.
} 
enables us to more closely examine the long-term stability of trends in treated and untreated units.

Figure 1 plots the turnout dynamics in treated and untreated cantons over event time, where the event of interest is the introduction of postal voting. We find that turnout levels evolve almost perfectly parallel in the period prior to the availability of postal voting, and even when going further back in time, the two time series still follow the same pattern. This is reflected in the pre-treatment difference-in-differences also shown in Figure 1: These differences are very close to zero throughout the pre-treatment period. The stability observable in this placebo test means that turnout in treated and control units evolved similarly even when assessing turnout up to five years before the introduction of postal voting. This adds to the plausibility of the assumption that in the absence of postal voting, turnout would have followed the trend observable in the control units.

Figure 1: Turnout in Referendums by Postal Voting, 1981-2009

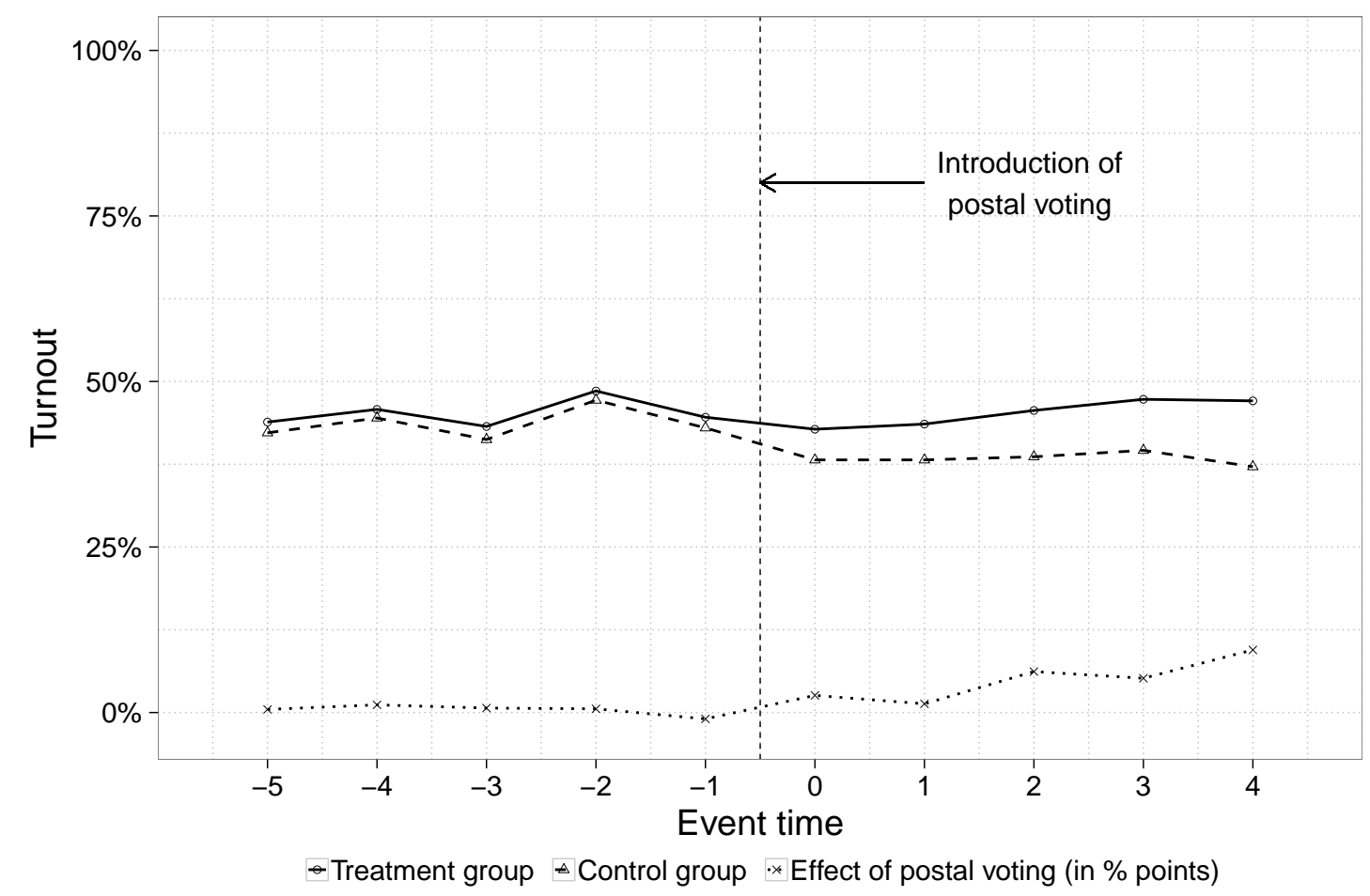

Note: Dots indicate average turnout in referendums (with $95 \%$ confidence intervals) for the pre-treatment and treatment period in cantons with postal voting versus cantons without postal voting. 
In addition to this non-parametric approach, we estimate the placebo effects using a linear regression model that includes canton and year fixed effects. These results (reported in detail in Appendix Table A.1) suggest that the placebo effects were zero and, if anything, slightly negative prior to the electoral reform. Overall, these results suggest that the assumption of parallel trends seems plausible in our application.

\section{Estimating the Mobilization Effect}

We now estimate the mobilization effect of postal voting. We employ linear probability models since we are only interested in marginal effects at this point and cluster standard errors by referendum day. The results remain unchanged when estimated using our individual-level data in combination with a probit model (see Appendix Table A.2). As can be seen from Model 1 in Table 1, turnout in referendums increases by 5 percentage points on average. The effect is precisely estimated with a standard error of .01 , which equals a $t$-value of 5 . Models 2 and 3 add canton and year fixed effects (Model 2) and socio-demographic control variables (Model 3, see the Appendix for a detailed description of all variables). Our estimated effect remains unchanged in terms of magnitude and significance.

This mobilization effect is equivalent to about 225,000 additional voters per referendum and is in line with previous estimates (Hodler, Luechinger and Stutzer 2015; Luechinger, Rosinger and Stutzer 2007). When benchmarked against previous results, the mobilization effect seems also sizeable in relative terms. For example, Brady and McNulty (2011) conclude "that changing polling places in Los Angeles County reduced turnout by a substantial 1.85\% among those who had their polling places changed" (p. 128) and even when compared to more socially invasive, field-experimental benchmarks, our estimate seems significant in terms of magnitude: Gerber, Green and Larimer (2008) devise a powerful get-out-the vote intervention that threatened subjects to inform neighboring households about their voting record. Receiving such a letter increases turnout by 8 percentage points on average. Given the social harmlessness of making postal voting available, our estimate of 5 percentage points 
seems all the more noteworthy.

\section{Decomposing the Mobilization Effect of Postal Voting}

Although postal voting significantly increases citizen participation in referendums, we still have to explore whether it mobilizes equally or unequally across political and socio-demographic subgroups of the population and how this translates into changes in the exact composition of turnout. Addressing this question is important because many studies have documented that electoral choice correlates significantly with socio-demographic and political characteristics (Nevitte et al. 2009; Verba, Schlozman and Brady 1995). To explore whether this correlation is also present in our data, we model an individual's vote over each referendum proposal as a function of political (political interest, party identification, ideological orientation, trust in government) and socio-demographic (age, education, employment, gender, religious denomination, place of residence language) variables. Figure 5 in the Appendix reports the share of coefficients that are significant at the 10 percent level in these estimations. We find that variables such as party identification, ideology, and trust in government tend to be significant predictors of vote choice in referendums. The results also suggest that some of the socio-demographic characteristics help predict variation in individual preferences over referendum proposals. These findings underscore the idea that the outcome of direct-democratic decisions may change depending on the heterogeneity in the mobilization effects of postal voting. Therefore, a comprehensive evaluation of the effect of postal voting needs to consider if postal voting mobilizes along those political and socio-demographic dimensions.

How does postal voting affect the turnout probabilities of different voter groups? To answer this question we first partition our individual-level data into theoretically meaningful political and sociodemographic subsets. Second, for each of these subsets we model an individual's turnout decision as a function of the availability of postal voting and a full set of canton and referendum-day fixed effects. The coefficient on the postal voting indicator 
provides us with an estimate of postal voting's effect on the probability of participating in a referendum. Employing such a group-specific regression approach instead of a multiple regression model is necessary, because we would like to know how postal voting mobilizes along a specific dimension allowing for the possibility that it also affects the composition of turnout on other dimensions. A multiple regression model would answer a different question, i.e., how strongly postal voting would affect the turnout probability of individuals with a specific characteristic (e.g. high income) assuming all other characteristics remain constant, which is not the question we would like to answer.

Figure 2 reports the results from these estimations graphically. We find that postal voting has a significantly positive effect on supporters of leftist parties: Individuals that report to identify with leftist parties have a six percentage points higher turnout probability under postal voting. We find a roughly similar effect for indviduals that feel attached to the conservative CVP, the liberal FDP, and other parties. In contrast, postal voting does not significantly increase turnout among those that identify with rightist parties. This is consistent with Hypothesis 1 and suggests that postal voting has differential mobilization effects on different partisan groups.

When examining the consequences of postal voting for the ideological composition of turnout, we find a significantly positive and almost uniform impact on different ideology groups. On average, individuals placing themselves on the left of the ideological spectrum have a 5 percentage points higher probability of turning out and this effect remains virtually identical when considering individuals in the ideological center and those on the right of the left-right spectrum. This result contradicts Hypothesis 2, but is consistent with our results on the differential effects by partisanship because many individuals that position themselves on the left or in the middle of the ideology dimension tend to identify with the CVP and the FDP.

One of the potential, negative side effects of postal voting is that it may mostly activate constituencies with low political interest and less political knowledge which may affect the 
Figure 2: The Effect of Postal Voting on the Probability of Turnout in Referendums

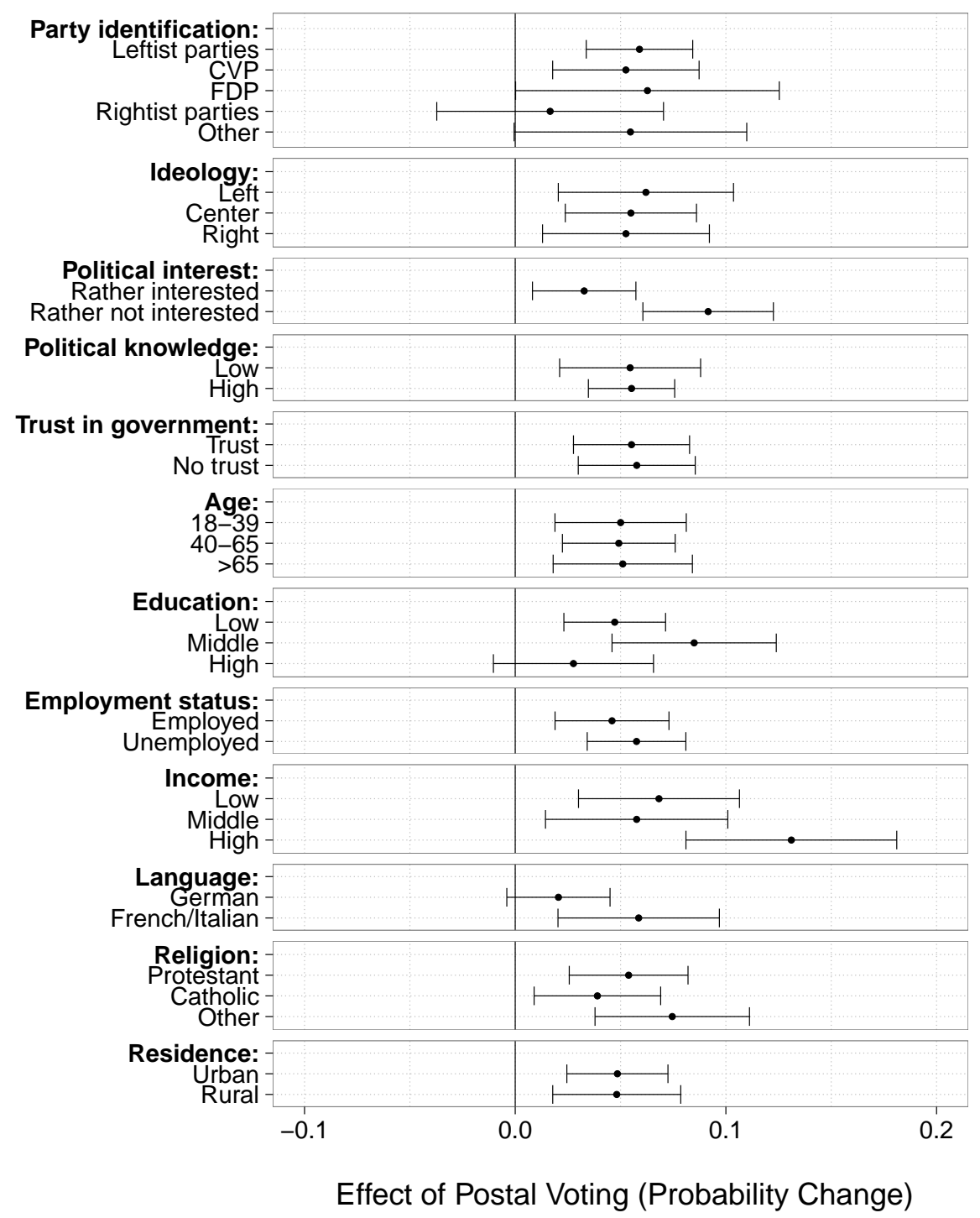

Note: The dots indicate how the introduction of postal voting affects the probability of turnout together with 95\%-confidence interval (horizontal error bars). Estimates are based on regressions for each group. Standard errors are clustered by referendum day. The sample sizes vary between 670 and 6,042 respondents per referendum day. Total $\mathrm{N}=79,041$ respondents that considered 239 proposals on 81 referendum days in the period 1981-2009.

quality of electoral choice. As Figure 2 shows, when estimating the turnout effect of postal voting on those who report to be interested in politics, we find a small and significant effect of about 3 percentage points. For the politically less interested, however, we estimate the effect at 8 percentage points. This supports the expectation that postal voting more strongly activates individuals with low levels of political interest (Hypothesis 3). One may worry 
that this could also mean that postal voting more strongly mobilizes individuals who are less informed about political issues, which may adversely affect the quality of electoral choice. Alternatively, even if individuals describe themselves as having little interest in politics, they may nevertheless be informed about the content and implications of ballot propositions.

To explore this question we directly measure political knowledge using two quiz items. The first question asks respondents to name the title of each proposal. The second question asks respondents to roughly describe the content of each proposal. We code respondents as knowledgeable if they answer both questions correctly. When estimating the turnout impact of postal voting by levels of political knowledge, we find an almost identical effect of 6 percentage points for both, those with low and those with high knowledge. This seems inconsistent with the argument that electoral institutions aiming to increase civic engagement most strongly activate citizens whose lack of political knowledge could adversely affect the quality of democratic choice. We also find significant and largely uniform effects when exploring the effect of postal voting on the composition of turnout in terms of individuals' trust in government (6 percentage points), across different age groups (5 percentage points), employment status ( 4 to 6 percentage points), religious denomination ( 4 to 7 percentage points), and place of residence (5 percentage points).

In terms of respondents' levels of formal education, we find that postal voting more strongly mobilizes citizens with low (5 percentage points) and medium levels of education (7 percentage points). Yet, we cannot reject the null that the estimates for those with low and high education are equal (Hypothesis 5). This, again, suggests that postal voting may not cause a turnout composition that contains a higher share of individuals less capable of making reasonable political decisions. We also explore how postal voting affects turnout among different income groups. We find that postal voting significantly increases participation among all income groups, although the effect sizes differ. Turnout under postal voting comprises about 6 percentage points more low earners and 5 percentage points more individuals with medium incomes. Among high earners, however, this effect more than doubles (13 
percentage points). This suggests that, although postal voting significantly increases civic engagement among all income groups, it has the most pronounced impact on those with high incomes, which is consistent with the opportunity cost argument (Hypothesis 6).

The finding that postal voting mobilizes both less interested individuals and high earners may seem counterintuitive because one would expect these two groups to be almost mutually exclusive. The empirics, however do not support this assumption. Although the two variables correlate, we find that even in the highest income category about $26 \%$ describe themselves as not being very interested in politics while for those in the lowest income category this figure is $41 \%$.

\section{Mapping the Composition of Turnout}

The results above provide information about the heterogeneity in the mobilization effect of postal voting. While informative, we still have to compute and map the precise composition of turnout in terms of each constituency's share with and without postal voting. Moreover, an assessment of whether electoral institutions such as postal voting increase or decrease representational inequality in turnout additionally requires a comparison with the votingeligible population (see section ). To explore the composition of turnout with and without postal voting we use the estimates from our main models and compute predicted levels of turnout for each subgroup. Figure 3 reports these quantities graphically along with the distributions in the voting-eligible population.

How does postal voting affect the make-up of turnout in terms of its ideological and partisan composition? After all, the mobilization effects of electoral reforms on voters that hold different ideological convictions and partisan attachments may give rise to notable shifts in both electoral outcomes and public policy. Despite the significant and sizable increase in aggregate-level turnout, we find that postal voting leaves the shares of different partisan identifiers almost unaffected. For example, in the voting-eligible population, individuals 


\section{Figure 3: The Composition of Turnout With and Without Postal Voting}

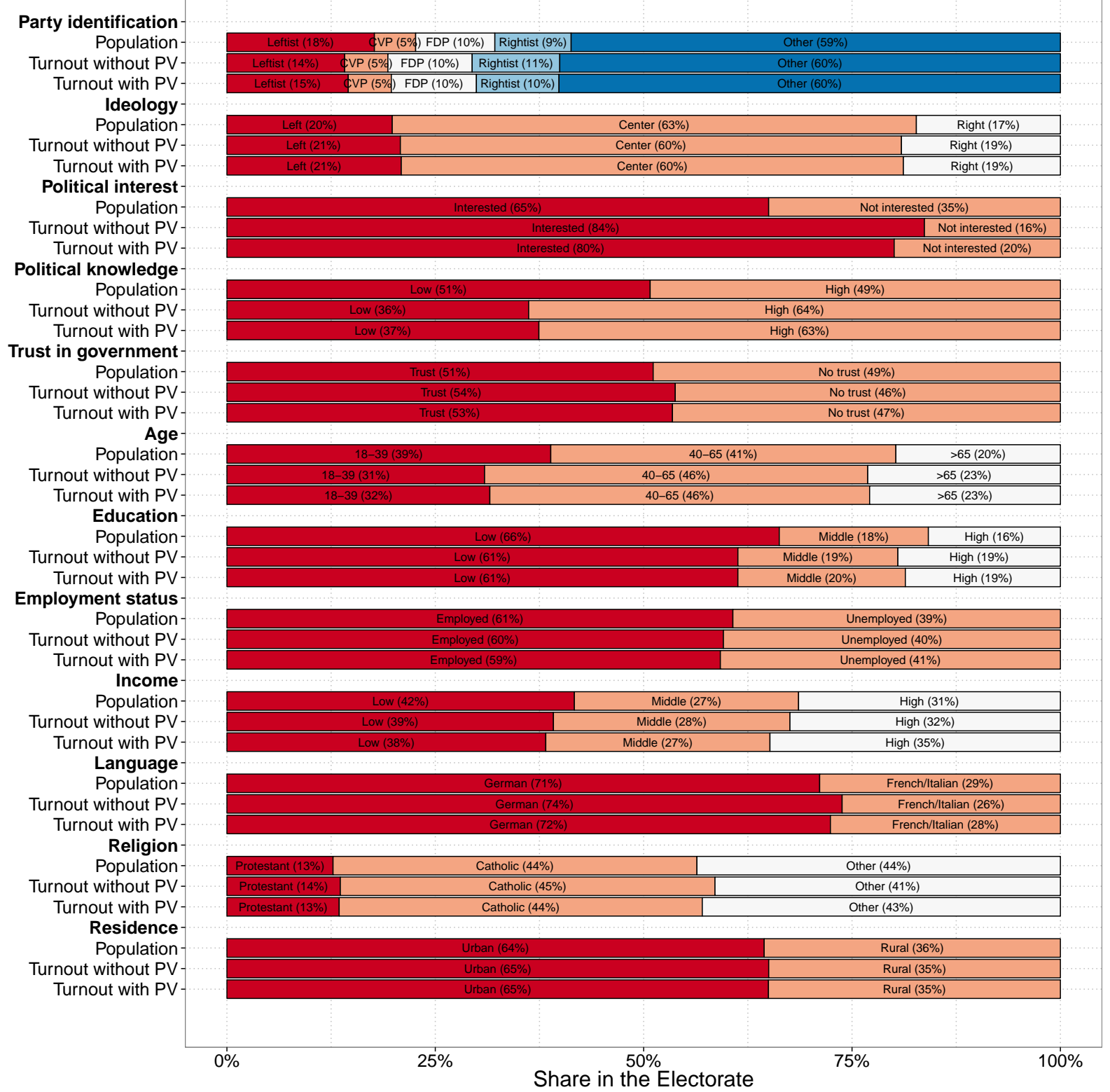

Note: This plot shows the shares of political and socio-demographic subgroups in the population and in the composition of turnout without postal voting and with postal voting. CVP=Christian Democratic People's Party, FDP $=$ Free Democratic Party. Estimates are based on an analysis of post-referendum surveys conducted among 79,041 respondents that considered 239 proposals on 81 referendum days in the period 1981-2009. 
identifying with leftist parties account for $18 \%$ of all partisans. When examining the partisan composition of turnout, we find that $14 \%$ support leftist parties without postal voting and this figure increases negligibly to $15 \%$ under postal voting. We also find only marginal or even no effects for other partisan identifiers.

To what extent to we find the same degree of stability in the composition of turnout when examining voters' ideological orientations? Our results suggest that in the population of eligible voters there exist $20 \%$ leftist individuals, $63 \%$ place themselves in the center of the ideological left-right dimension, and $17 \%$ are located on the right of the ideological spectrum. Our results indicate that turnout with and without postal voting quite closely mirrors this distribution. Thus, despite the significant and substantial turnout increase documented above, we find that postal voting leaves the ideological composition of turnout virtually unchanged.

Although we find only moderate differential effects on the political composition of turnout, higher turnout could still come at the cost of increasing the share of voters with low levels of political interest and knowledge, which may adversely affect the quality of direct-democratic choice. Although our results suggest that the share of voters that are interested in political issues decreases from $84 \%$ to about $80 \%$, this does not seem to imply that these voters are less knowledgeable. In fact, the share of politically knowledgeable voters stays virtually unchanged after the introduction of postal voting and continues to remain substantially higher than in the voting-eligible benchmark population (51\%). This suggests that higher turnout does not necessarily imply that voters become less politically knowledgeable. Instead, the finding is consistent with a dynamic model of civic engagement in which citizens who decide to participate politically become more informed about the issues at stake, even if they remain less interested in politics in general. 


\section{The Policy Consequences of Postal Voting}

A central question in the study of electoral reforms is whether institutional change actually has policy consequences. This question is important even if each of the shifts in the sociodemographic and ideological composition of turnout appear modest because a combination of the differential changes we have identified could still add up to notable changes in electoral support for specific ballot propositions. To explore the policy consequences of postal voting we simulate the outcomes of close referendums with and without postal voting. We focus on proposals that have been accepted or rejected by an 8 percentage points margin as it seems unlikely that the effects we document could be decisive for any ballot measures that received much higher or much lower levels of electoral support. This leaves us with 22 policy proposals. For these 22 ballot measures we simulate the share of yes votes without postal voting and with postal voting. This simulation relies on our estimates of the mobilization

effects of postal voting and the estimates we derive from our analysis of the predictors of voting on ballot propositions (see Figure 5 in the Appendix and Section ). We first predict the level of support for each ballot measure without postal voting by multiplying each constituents' share in the composition of turnout with the corresponding coefficient from the estimated vote choice equation. We predict the level of support under postal voting analogously but now accounting for the higher share of high-income individuals and the higher share of less politically interested voters. Figure 4 reports these results graphically along with the observed yes share for each ballot proposition. While we believe these point predictions to be interesting and informative, we note that they are associated with various types of uncertainty that are difficult to quantify because the results rely on two different sets of estimated parameters and also rest on assumptions about the intertemporal and cross-sectional stability of our estimates.

Keeping this caveat in mind, we find that most of the referendum outcomes remain unchanged by the introduction of postal voting. In other words, in most close referendums the introduction of postal voting does not turn a rejected proposal into one that receives at 
Figure 4: The Policy Consequences of Postal Voting in Close Referendums

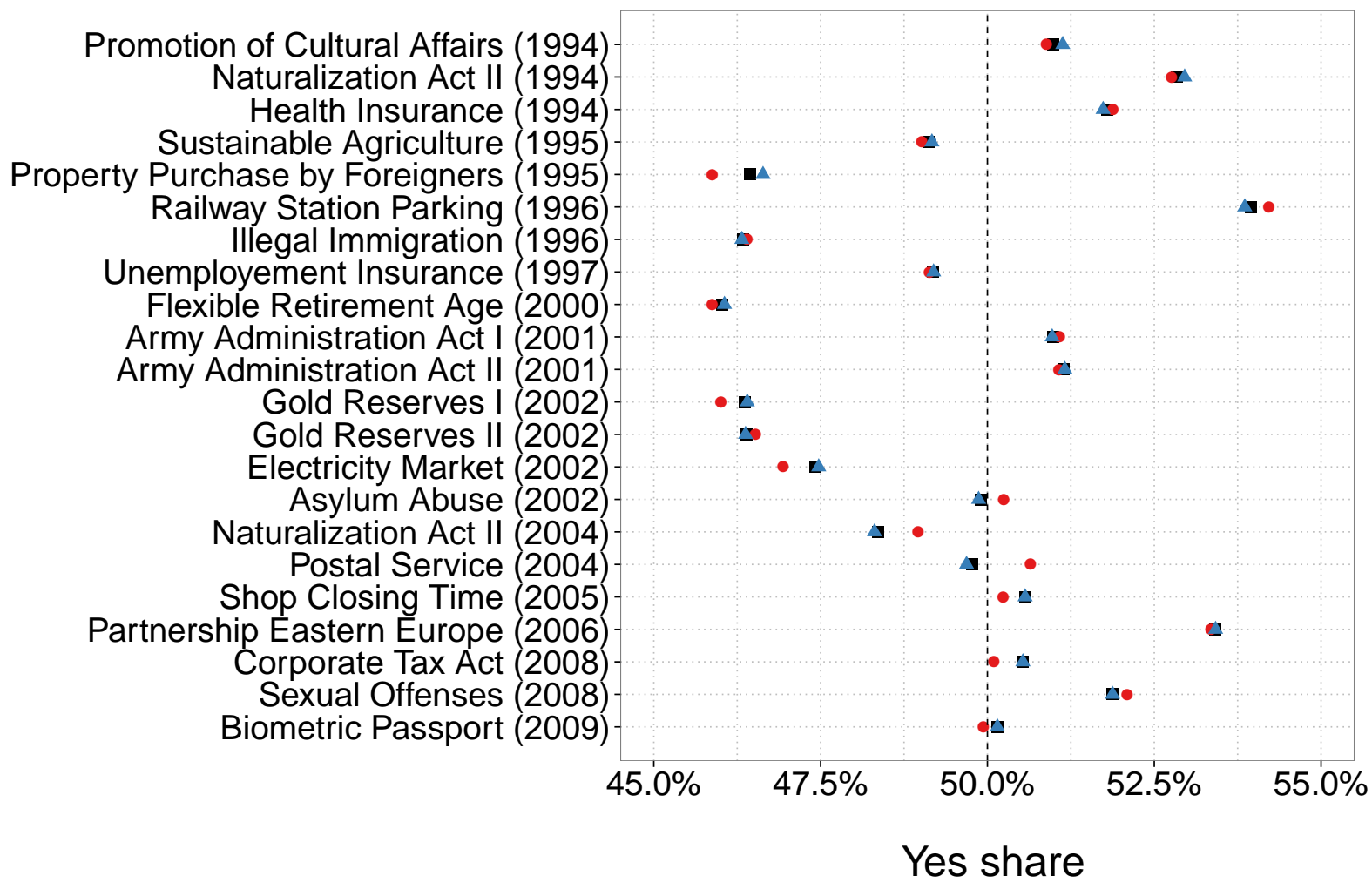

- Observed • No Postal Voting $\triangle$ Postal Voting

\begin{abstract}
Note: This plot shows the observed and predicted yes shares with and without postal voting for the 22 closest out of 230 referendum proposals in total $(50+/-4$ percentage points). The dashed vertical line indicates the $50 \%$ threshold. The predicted yes shares are based on an analysis of post-referendum surveys conducted on representative samples. Total N=79,041 respondents that considered 239 proposals on 81 referendum days in the period 1981-2009.
\end{abstract}

least $50 \%$ of the votes or, alternatively, transforms a winning proposal into one that would be rejected. However, for some extremely conflictual ballot propositions, postal voting likely was consequential: Our simulations suggest that the popular initiative "Against Asylum Abuse" launched by the right-wing Swiss People's Party, which missed majority support (49.9\%) in 2002 may have passed without postal voting (50.2\%) since by that time virtually all cantons had introduced postal voting. The availability of postal voting may also have made the difference between rejection and adoption in the case of the postal service initiative which demanded a denser net of post offices (2004). Under postal voting, the initiative received 49.8 yes votes while we predict that without postal voting it would have been supported by 
about $50.6 \%$. A third ballot measure for which the changes in the composition of turnout due to postal voting would probably have been decisive is the referendum on the introduction of biometric passports in 2009. 50.14\% supported the introduction of biometric passports. Without postal voting, however, the referendum may have been rejected by a slim majority of voters. Since postal voting appears to have been potentially consequential for only three out of 22 extremely close referendums (out of 239 proposals in total). We interpret this as tentative evidence indicating that the policy impact of postal voting was presumably small.

\section{Conclusion}

Voting is not a costless activity and these costs are felt differently across groups that hold different policy preferences and vary in their ability to engage in political decisionmaking. How do changes in the costs of voting affect representational inequality and electoral choice? While some deem higher levels of political participation normatively desirable to increase democratic legitimacy, others worry about whether turnout increases may negatively affect the quality of collective decisionmaking. We contribute to this debate by studying the introduction of postal voting as an electoral reform meant to foster political participation in direct legislation. By exploiting the sequential introduction of postal voting in Switzerland and analyzing large amounts of individual-level data we are the first to decompose the turnout increase due to postal voting into its political and socio-demographic components. This enables us to map in detail how the composition of turnout responds to an exogenous decrease in the costs of voting in referendums.

We find that postal voting increases turnout by five percentage points on average, a magnitude that appears sizeable if compared to the effects of much more invasive get-outthe-vote measures. For example, in a field experiment on turnout, intimidating mailings that listed the voting records of one's neighbors and threatened "to publicize who does and does not vote...to apply maximal social pressure" (Gerber, Green and Larimer 2008, 38) increased 
political participation by 8 percentage points. When exploring the potential heterogeneity in this effect we find significant increases across a large set of sociodemographic characteristics. However, postal voting most strongly activates citizens that are generally less interested in politics, high earners, and individuals with low and medium levels of education. To fully evaluate the impact of postal voting on the composition of turnout, we map in detail the share of different voter groups without and with postal voting. These results suggest that the consequences of postal voting on the political and socio-demographic composition of turnout are quite limited. Moreover, when we simulate the effects of postal voting on the outcomes of direct-democratic choice, we find that postal voting has quite limited effects on the referendum results.

These results offer implications for policymakers and suggest avenues for future research. First, since we find that the availability of voting by mail does not affect referendum outcomes, our results lessen concerns about the adverse consequences of postal voting on the quality of political choice. This is consistent with the finding that postal voting does not significantly increase the share of individuals with less political knowledge. Instead, we document that postal voting has significant and largely uniform effects on turnout among a large set of constituencies. Consequently, policymakers interested in increasing civic engagement across various sociodemographic, religious, and language groups may find postal voting a particularly attractive instrument. Second, we have examined the effect of a specific electoral institution that decreases the costs of voting on the detailed composition of turnout. To what extent do our results generalize to other types of institutions that affect individuals' voting costs? The cumulative evidence begins to suggest a notable degree of heterogeneity in how individuals respond to electoral reforms. These effects depend on the design of the modified institutions in terms of their specificity (e.g., poll taxes that disproportionately hurt the poor) and seem to be conditional on whether they alter the costs of voting (e.g., relocation of polling places, literacy tests) or the costs of non-voting (e.g., fining or socially shaming non-voters). The literature would benefit from a systematic study of how the design 
of electoral institutions along those two dimensions affects the composition of turnout and, in turn, public policy. Finally, given the large set of electoral reforms available to policymakers, future work may start exploring how the implementation of a sequence of reforms affects electoral behavior. For example, even if the effects of one single change in the costs of voting may remain modest, combining several institutional changes over time could have a profound impact on elections and public policy. Studying how sequences of electoral reforms affect political choice and the extent to which institutional changes interact seems a promising and interesting task for future research.

\section{References}

Bechtel, Michael M., Dominik Hangartner and Lukas Schmid. 2015. "Does Compulsory Voting Increase Support for Leftist Policy?" American Journal of Political Science forthcoming.

Bechtel, Michael M. and Jens Hainmueller. 2011. "How Lasting Is Voter Gratitude? An Analysis of the Short- and Lon-Term Electoral Returns to Beneficial Policy." American Journal of Political Science 55(4):851-867.

Berinsky, Adam J. 2005. "The Perverse Consequences of Electoral Reform in the United States." American Politics Research 33(4):471-491.

Berinsky, Adam J., Nancy Burns and Michael W. Traugott. 2001. "Who Votes by Mail? A Dynamic Model of the Individual-level Consequences of Voting-by-Mail Systems." Public Opinion Quarterly 65:178-197.

Biggers, Daniel R. and Michael J. Hanmer. 2015. "Who Makes Voting Convenient? Explaining the Adoption of Early and No-Excuse Absentee Voting in the American States." State Politics and Policy Quarterly 15(2):192-210.

Bolling, Richard. 1986. "Money in Politics." Annals of the American Academy of Political and Social Science 486(July):76-85.

Bowler, Shaun and Todd Donovan. 2000. Demanding Choices: Opinion, Voting, and Direct Democracy. Michigan: University of Michigan Press.

Brady, Henry E. and John E. McNulty. 2011. "Turning Out to Vote: The Costs of Finding and Getting to the Polling Place." American Political Science Review 105(1):115-134.

Burden, Barry, David T. Canon, Kenneth R. Mayer and Donald P. Moynihan. 2014. "Election Laws, Mobilization, and Turnout: The Unanticipated Consequences of Election Reform." American Journal of Political Science 58(1):95-109.

Butler, Daniel M. 2014. Representing the Advantaged: How Politicians Reinforce Inequality. New York: Cambridge University Press. 
Citrin, Jack, Eric Schickler and John Sides. 2003. "What if Everyone Voted? Simulating the Impact of Increased Turnout in Senate Elections." American Journal of Political Science 47(1):75-90.

Downs, Anthony. 1957. "An Economic Theory of Political Action in a Democracy." Journal of Political Economy 65(2):135-150.

Feddersen, Timothy J. 2004. "Rational Choice Theory and the Paradox of Not Voting." The Journal of Economic Perspectives 18(1):99-112.

Filer, John E., Lawrence W. Kenny and Rebecca B. Morton. 1993. "Redistribution, Income, and Voting." American Journal of Political Science 37(1):54-82.

Fowler, Anthony. 2013. "Turnout Matters: Evidence from Compulsory Voting in Australie." Quarterly Journal of Political Science 8(1):1-24.

Fraga, Bernard. 2011. "Voting Costs and Voter Turnout in Competitive Elections." Quarterly Journal of Political Science 5(4):339-356.

Fujiwara, Thomas. 2015. "Voting Technology, Political Responsiveness, and Infant Health: Evidence from Brazil." Econometrica 83(2):423-464.

Galston, William A. 2001. "Political Knowledge, Political Engagement, and Civic Education." Annual Review of Political Science 4:217-234.

Gasper, John T. and Andrew Reeves. 2011. "Make It Rain? Retrospection and the Attentive Electorate in the Context of Natural Disasters." American Journal of Political Science 55(2):201462.

Gerber, Alan S., Donald P. Green and Christopher W. Larimer. 2008. "Social Pressure and Voter Turnout: Evidence from a Large-Scale Field Experiment." American Political Science Review 102(1):33-48.

Gibson, John, Kim Bonggeun, Steven Stillman and Geua Boe-Gibson. 2012. "Time to vote?" Public Choice pp. 1-20.

Gomez, Brad T., Thomas G. Hansford and George A. Krause. 2007. "The Republicans should pray for rain: Weather, turnout, and voting in US presidential elections." Journal of Politics 69(3):649-663.

Gronke, Paul and Peter Miller. 2012. "Voting by Mail and Turnout in Oregon. Revisiting Southwell and Burchett." American Politics Research 40(6):976-997.

Hodler, Roland, Simon Luechinger and Alois Stutzer. 2015. "The Effects of Voting Costs on the Democratic Process and Public Finances." American Economic Journal: Economic Policy $7(1): 141-171$.

Holbein, John B. and D. Sunshine Hillygus. 2016. "Making Young Voters: The Impact of Preregistration on Youth Turnout." American Journal of Political Science 60(2):1.

Husted, Thomas A. and Lawrence W. Kenny. 1997. "The Effect of the Expansion of the Voting Franchise on the Size of Government." Journal of Political Economy 105(1):54-82.

Jackman, Robert W. 1987. "Political Institutions and Voter Turnout in the Industrial Democracies." American Political Science Review 81(2):405-424. 
Ledyard, John O. 1984. "The pure theory of large two-candidate elections." Public Choice 44:7-41.

Leighley, Jan E. and Jonathan Nagler. 2007. "Voter and Class Bias in the Turnout, Unions, Electorate, 1964-2004." Journal of Politics 69(2):430-441.

Levine, David K. and Thomas R. Palfrey. 2007. "The Paradox of Voter Participation? A Laboratory Study." American Political Science Review 101(01):143.

URL: http://www.journals.cambridge.org/abstract_S0003055407070013

Lijphart, Arend. 1997. "Unequal participation: Democracy's unresolved dilemma." American Political Science Review 91(1):1-14.

Luechinger, S., M. Rosinger and A. Stutzer. 2007. "The Impact of Postal Voting on Participation: Evidence for Switzerland." Swiss Political Science Review 13(2):167-202.

Lupia, A. 1992. "Busy voters, agenda control, and the power of information." The American Political Science Review pp. 390-403.

Lupia, Arthur and Mathew D. McCubbins. 1998. The Democratic Dilemma: Can Citizens Learn What They Need to Know? Cambridge University Press.

Magleby, David B. 1984. Direct Legislation: Voting on Ballot Propositions in the United States. Baltimore: Johns Hopkins University Press.

McNulty, John E., Conor M. Dowling and Marggaret H. Ariotti. 2009. "Driving Saints to Sin: How Increasing the Difficulty of Voting Dissuades Even the Most Motivated Voters." Political Analyis 17(4):435-455.

Morton, Rebecca B., Daniel Muller, Lionel Page and Benno Torgler. 2015. "Exit Polls, Turnout, and Bandwagon Voting: Evidence from a Natural Experiment." European Economic Review forthcoming.

Nevitte, Neil, Andé Blais, Elisabeth Gidengril and Richard Nadeau. 2009. The Comparative Study of Electoral Systems. Cambridge: Cambridge University Press chapter Socioeconomic Status and Nonvoting: A Cross-National Comparative Analysis, pp. 88-105.

Nichter, Simoneon. 2008. "Vote Buying or Turnout Buying? Machine Politics and the Secret Ballot." American Political Science Review 102(1):19-31.

Palfrey, Thomas R. and Howard Rosenthal. 1983. "A strategic calculus of voting." Public Choice $41(1): 7-53$.

Palfrey, T.R. and Howard Rosenthal. 1985. "Voter participation and strategic uncertainty." American Political Science Review 79(1):62-78.

Panagopoulos, Costas. 2008. "The Calculus of Voting in Compulsory Voting Systems." Political Behavior 30(4):455-467.

Panagopoulos, Costas and Marisa A. Abrajano. 2014. "Life-Cycle Effects and Social Pressure to Vote." Electoral Studies 33:115-122.

Potrafke, Niklas and Felix Roesel. 2016. "Opening Hours of Polling Stations and Voter Turnout: Evidence from a Natural Experiment.". 
Riker, W.H. and P.C. Ordeshook. 1968. "A Theory of the Calculus of Voting." American Political Science Review 62(1):25-42.

Sinclair, Betsy, Thad E. Hall and R. Michael Alvarez. 2011. "Flooding the Vote: Hurricane Katrina and Voter Participation in New Orleans." American Politics Research 39(5):921-965.

Southwell, Priscilla and Justin Burchett. 1997. "Survey of Vote-by-Mail Senate Election in the State of Oregon." PS: Political Science and Politics 30(1):53-57.

Southwell, Priscilla and Justin Burchett. 2001. "Does Changing the Rules Change the Players? The Effect of All-Mail Elections on the Composition of the Electorate." Social Science Quarterly $81(3): 837-845$.

Tucker, Harvey J., Arnold Vedlitz and James DeNardo. 1986. "Does Heavy Turnout Help Democrats in Presidential Elections?" American Political Science Review 80(4):1291-1304.

Verba, Sidney, Kay L. Schlozman and Henry E. Brady. 2000. "Rational Action and Political Activity." Journal of Theoretical Politics 12(3):243-268.

Verba, Sidney, Kay Lehman Schlozman and Henry E. Brady. 1995. Voice and Equality: Civic Voluntarism in American Politics. Cambridge: Harvard University Press.

Zaller, John R. 1992. The Nature and Origins of Mass Opinion. New York: Cambridge University Press. 


\section{Appendix}

\section{Figures}

Figure 5: Predictors of Vote Choice in Referendums, 1981-2009

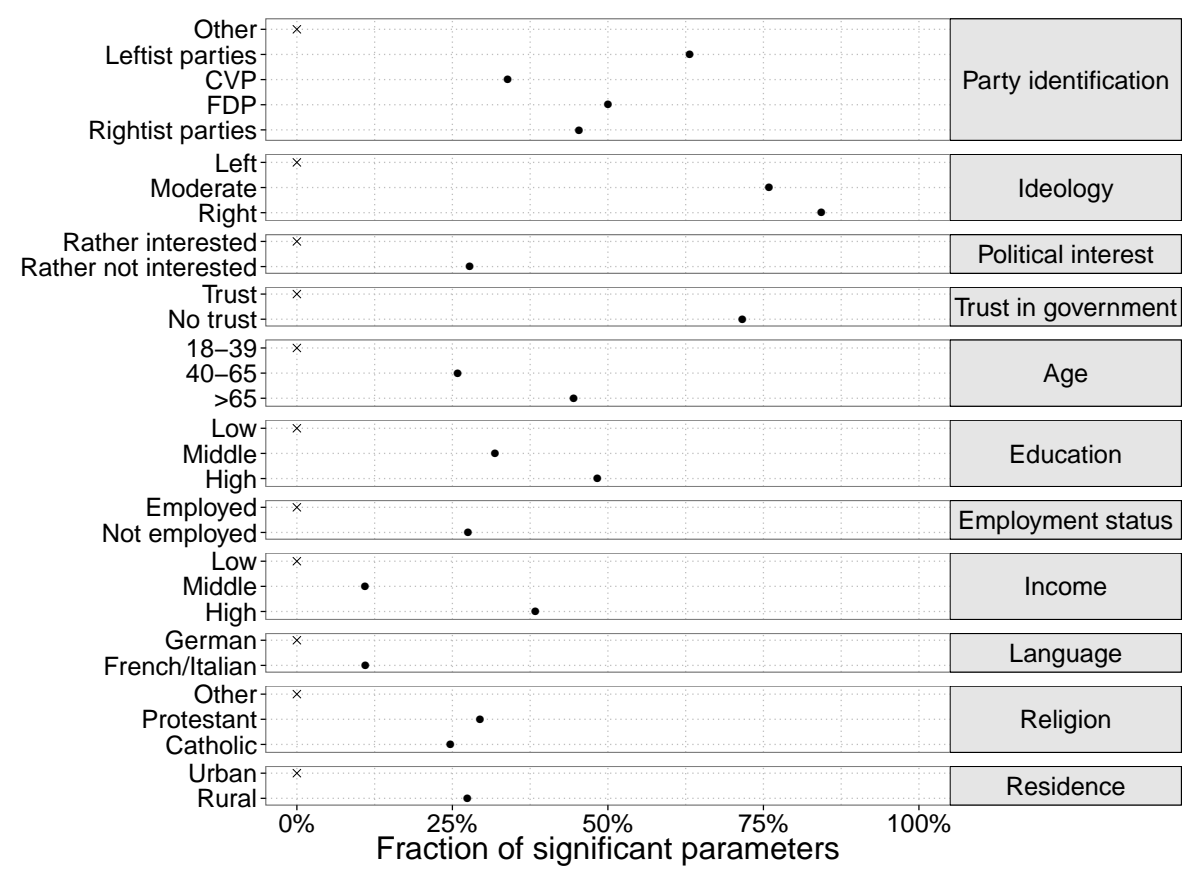

Note: Dots indicate the share of ballot-specific regressions in which a variable was a significant (at the 10 percent level) predictor of vote choice. Crosses indicate reference categories. All regressions model vote choice as a function of the same set of socio-demographic and political predictors for each ballot proposition with standard errors clustered by referendum day. Total $\mathrm{N}=79,041$ respondents. The sample sizes vary between 670 and 6,042 respondents per referendum day. 
Figure 6: Predicted Turnout Probabilities in Referendums with and without Postal Voting, 1981-2009

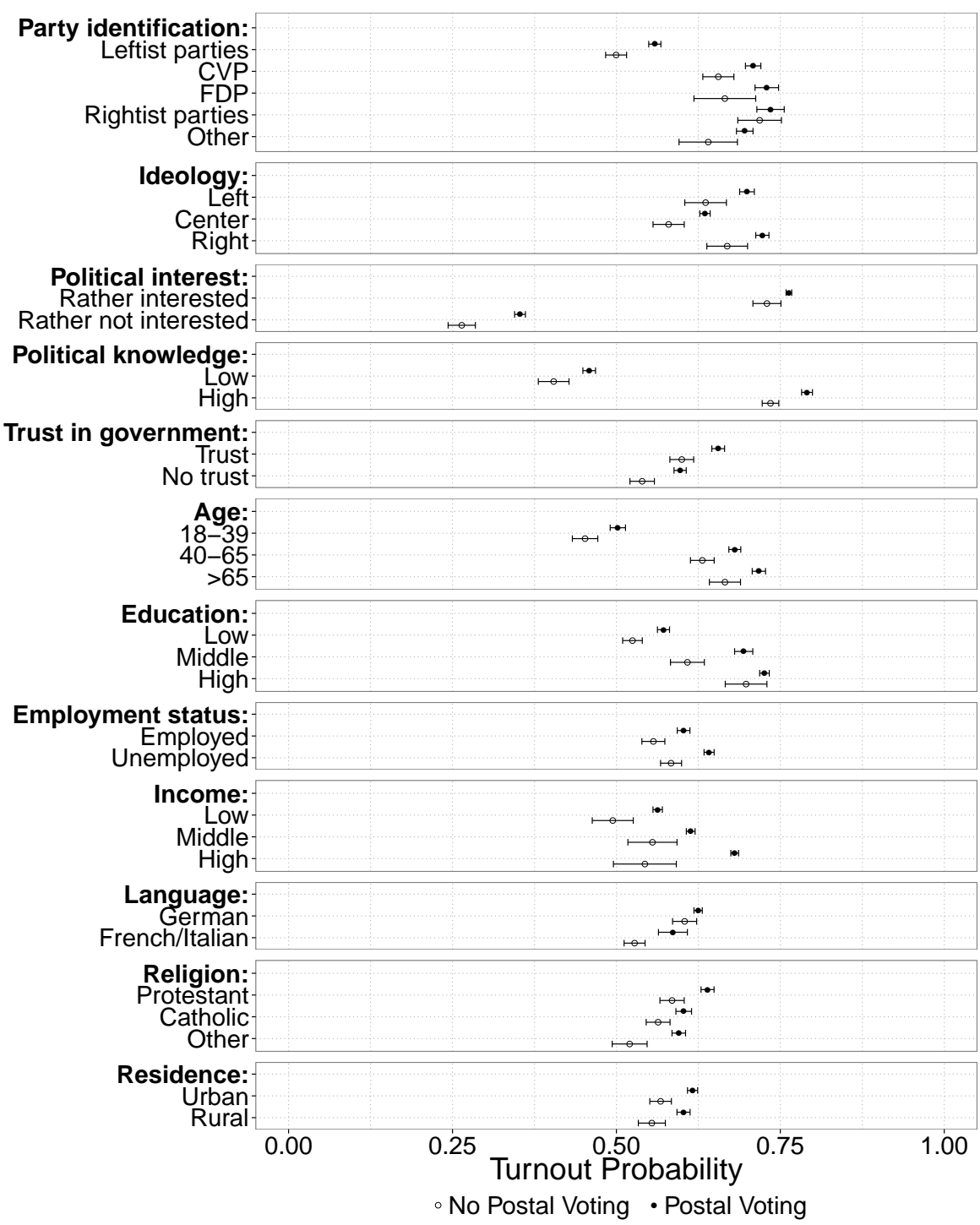

Note: Black dots indicate the predicted turnout probabilities under postal voting and white circles indicate the predicted turnout probabilities without postal voting. Horizontal lines indicate 95\%-confidence intervals. All estimates are based on group-specific regressions that include canton and referendum-day fixed effects. Total $\mathrm{N}=79,041$ respondents from representative samples. The sample sizes vary between 670 and 6,042 respondents per referendum day. Standard errors are clustered by referendum day. 


\section{Tables}

Table 1: Postal Voting and Turnout in Referendums, 1981-2009

\begin{tabular}{lccc}
\hline \hline & $(1)$ & $(2)$ & $(3)$ \\
\hline Postal Voting & 0.05 & 0.05 & 0.05 \\
& $(0.01)$ & $(0.01)$ & $(0.01)$ \\
\hline Observations & 78,464 & 73,443 & 69,116 \\
R-squared & 0.00 & 0.04 & 0.10 \\
\hline Controls & & & $\checkmark$ \\
Canton FE & & $\checkmark$ & $\checkmark$ \\
Year FE & & $\checkmark$ & $\checkmark$
\end{tabular}

Note: The table reports OLS regression coefficients. The dependent variable is turnout in referendums. The control variables (controls) are: Share of individuals 60 years or older, share of individuals holding a university degree), aggregatelevel results, share of catholics in the canton. The appendix provides a detailed description of all variables. Standard errors are clustered by referendum day. The results remain unchanged when estimated using individual-level data (see Appendix Table A.2). 
Table 2: Introduction of Postal Voting in Switzerland

\begin{tabular}{|c|c|c|c|c|c|}
\hline & \multirow[t]{2}{*}{ Canton } & \multicolumn{2}{|c|}{ Postal voting for a restricted group of persons } & \multicolumn{2}{|c|}{ Postal voting for all citizens } \\
\hline & & On request $(\mathrm{rr})$ & No request necessary $(\mathrm{rn})$ & On request (ar) & No request necessary (an) \\
\hline 1 & Zuerich (ZH) & 17.12 .1955 & & 01.01 .1985 & 01.10 .1994 \\
\hline 2 & Bern (BE) & 01.01 .1967 & 01.05 .1970 & & 01.07 .1991 \\
\hline 3 & Luzern (LU) & 01.01 .1967 & & 01.12 .1978 & 01.10 .1994 \\
\hline 4 & Uri (UR) & 04.06 .1967 & & & 01.01 .1995 \\
\hline 5 & Schwyz (SZ) & 08.10 .1971 & & 01.03 .1992 & 01.01 .2000 \\
\hline 6 & Obwalden (OW) & 01.04 .1974 & & 01.07.1978 & 01.12 .1995 \\
\hline 7 & Nidwalden (NW) & & & 20.12.1979 & 29.06.1994 \\
\hline 8 & Glarus (GL) & 01.01 .1967 & & & 01.07 .1995 \\
\hline 9 & Zug (ZG) & 01.07.1969 & & & 01.04 .1997 \\
\hline 10 & Fribourg (FR) & 19.09.1966 & & 01.09 .1976 & 23.05 .1995 \\
\hline 11 & Solothurn (SO) & & & 01.01.1981 & 01.01 .1985 \\
\hline 12 & Basel-Stadt (BS) & 13.06 .1976 & & & 30.12 .1994 \\
\hline 13 & Basel-Landschaft (BL) & 01.05 .1962 & & & 01.07 .1978 \\
\hline 14 & Schaffhausen (SH) & 22.03 .1968 & & & 01.08 .1995 \\
\hline 15 & Appenzell Ausserrhoden (AR) & 01.01 .1967 & & & 24.05 .1988 \\
\hline 16 & Appenzell Innerrhoden (AI) & & & & 11.06.1979 \\
\hline 17 & St. Gallen (SG) & 01.06 .1967 & & & 01.05 .1979 \\
\hline 18 & Graubuenden (GR) & 01.01 .1967 & & & 01.01 .1995 \\
\hline 19 & Aargau (AG) & 01.01 .1967 & & & 01.01 .1993 \\
\hline 20 & Thurgau (TG) & 01.01 .1967 & 01.09 .1978 & & 01.08 .1985 \\
\hline 21 & Ticino (TI) & 01.12 .1998 & & & 15.04 .2005 \\
\hline 22 & Vaud (VD) & 07.02 .1979 & & 01.01 .1990 & 25.03 .2002 \\
\hline 23 & Valais (VS) & 01.10 .1972 & & 01.10 .1996 & 01.01 .2005 \\
\hline 24 & Neuchatel (NE) & 01.01 .1967 & & 26.04 .1995 & 01.01 .2001 \\
\hline 25 & Geneva (GE) & 25.06 .1950 & & & 01.01 .1995 \\
\hline 26 & Jura (JU) & 01.01.1979 & & & 01.05.1999 \\
\hline
\end{tabular}

Note: This overview reports when each canton introduced which type of postal voting. All cantons eventually introduced postal voting with each eligible citizen automatically receiving the ballot by mail. Citizens can then either return the ballot by mail or at a polling station. Source: (Luechinger, Rosinger and Stutzer 2007). 


\section{Appendix}

\section{Variable Definitions}

- Party Identification: Measures partisan identification. Question wording: "Which of the following parties corresponds most with your political opinion?" Answer categories: Social-Democratic Party (SPS), Christian Democratic People's Party (CVP), Free Democratic Party (FDP), Swiss People's Party (SVP), Other.

- Ideology: Self-reported placement on left-right ideology scale. Question wording: "In politics people often talk of 'left' and 'right'. If you use a scale from 0 to 10, where would you classify your own political views on this scale from left (0) to right (10)? The measure used in the analysis classifies individuals with a value from 0 to 3 as "Left", those with a value from 4 to 6 as "Moderate", and those with a value from 7 to 10 as "Right".

- Political Interest: Binary indicator that discriminates between respondents indicating that they tend to be rather interested in politics and those that report rather not interested.

- Political Knowledge: Binary indicator that distinguishes between respondents that were able to answer two objective knowledge questions and those that were not. The first question asked respondents to name the title of each proposal. The second question asked respondents to roughly describe the content of each proposal. We code respondents as knowledgeable if they answered both questions correctly.

- Trust in Government: Measures trust in government. Question wording: "Which of the following statements corresponds with your opinion about the federal government." Answer categories: $1=$ "Most of the time I trust in our federal government. It acts for the good of all citizens.", $2=$ "Sometimes decisions in the federal government are taken against the people. The government is not aware of our preoccupations."

- Age: Age of respondent in years. For the aggregate-level analysis this variable measures the share of individuals 60 years or older.

- Education: Measures respondent's highest level of completed education. Answer categories: Low (mandatory schooling and vocational training), Medium (high school and post-vocational training), High (university of applied sciences and university). For the aggregate-level analysis, this variable measures the share of respondents holding a university degree.

- Employment Status: Binary indicator that discriminates between respondents who are employed and respondents who are not employed.

- Income: Self-reported monthly household income. Answer categories: Low (< EUR 3,333); Medium (EUR 3,334-4,667 ); High (>EUR 4,667 Euro).

- Language: Binary indicator for native language that distinguishes between German and French/Italian.

- Religion: Religious denomination. For the aggregate-level analysis this variable records the share of respondents that identify themselves as belonging to any of the following religious denominations: Protestant, Catholic, Other.

- Residence: Binary indicator for residence. Answer categories: Urban, rural. 
Table A.1: Placebo Tests for Turnout and Postal Voting, 1981-2009

\begin{tabular}{|c|c|c|c|c|}
\hline & (1) & $(2)$ & (3) & (4) \\
\hline Pre-treatment: $t-5$ & $\begin{array}{c}0.004 \\
(0.016)\end{array}$ & $\begin{array}{c}0.005 \\
(0.015)\end{array}$ & $\begin{array}{l}-0.000 \\
(0.011)\end{array}$ & $\begin{array}{c}0.000 \\
(0.007)\end{array}$ \\
\hline Pre-treatment: $t-4$ & $\begin{array}{c}0.007 \\
(0.028)\end{array}$ & $\begin{array}{c}0.006 \\
(0.027)\end{array}$ & $\begin{array}{l}-0.009 \\
(0.010)\end{array}$ & $\begin{array}{l}-0.012^{*} \\
(0.006)\end{array}$ \\
\hline Pre-treatment: $t-3$ & $\begin{array}{l}-0.008 \\
(0.019)\end{array}$ & $\begin{array}{l}-0.010 \\
(0.018)\end{array}$ & $\begin{array}{l}-0.002 \\
(0.009)\end{array}$ & $\begin{array}{l}-0.005 \\
(0.006)\end{array}$ \\
\hline Pre-treatment: $t-2$ & $\begin{array}{c}0.027 \\
(0.027)\end{array}$ & $\begin{array}{c}0.024 \\
(0.027)\end{array}$ & $\begin{array}{l}-0.011 \\
(0.010)\end{array}$ & $\begin{array}{c}-0.016^{* *} \\
(0.007)\end{array}$ \\
\hline Pre-treatment: $t-1$ & $\begin{array}{c}0.006 \\
(0.010)\end{array}$ & $\begin{array}{c}0.002 \\
(0.010)\end{array}$ & $\begin{array}{l}-0.003 \\
(0.008)\end{array}$ & $\begin{array}{l}-0.009^{*} \\
(0.005)\end{array}$ \\
\hline Postal Voting & $\begin{array}{c}0.014 \\
(0.012)\end{array}$ & $\begin{array}{c}0.012 \\
(0.014)\end{array}$ & $\begin{array}{c}0.036^{* * *} \\
(0.009)\end{array}$ & $\begin{array}{c}0.033 * * * \\
(0.008)\end{array}$ \\
\hline Postal Voting $t+1$ & $\begin{array}{c}0.016 \\
(0.013)\end{array}$ & $\begin{array}{c}0.014 \\
(0.012)\end{array}$ & $\begin{array}{c}0.032^{* * *} \\
(0.006)\end{array}$ & $\begin{array}{c}0.030 * * * \\
(0.006)\end{array}$ \\
\hline Postal Voting $t+2$ & $\begin{array}{c}0.036^{* * *} \\
(0.012)\end{array}$ & $\begin{array}{c}0.034^{* * *} \\
(0.011)\end{array}$ & $\begin{array}{c}0.031^{* * *} \\
(0.007)\end{array}$ & $\begin{array}{c}0.029 * * * \\
(0.006)\end{array}$ \\
\hline Postal Voting $t+3$ & $\begin{array}{c}0.047^{* * *} \\
(0.014)\end{array}$ & $\begin{array}{c}0.045^{* * *} \\
(0.013)\end{array}$ & $\begin{array}{c}0.033^{* * *} \\
(0.005)\end{array}$ & $\begin{array}{c}0.030 * * * \\
(0.005)\end{array}$ \\
\hline Postal Voting $t+4$ & $\begin{array}{c}0.041^{* *} \\
(0.016)\end{array}$ & $\begin{array}{c}0.036^{* *} \\
(0.016)\end{array}$ & $\begin{array}{c}0.029^{* * *} \\
(0.006)\end{array}$ & $\begin{array}{c}0.023^{* * *} \\
(0.005)\end{array}$ \\
\hline Postal Voting $t+5$ & $\begin{array}{c}0.054^{* * *} \\
(0.014)\end{array}$ & $\begin{array}{c}0.048^{* * *} \\
(0.014)\end{array}$ & $\begin{array}{c}0.025^{* * *} \\
(0.004)\end{array}$ & $\begin{array}{c}0.017^{* * *} \\
(0.005)\end{array}$ \\
\hline Observations & 2,225 & 2,225 & 2,225 & 2,225 \\
\hline R-squared & 0.026 & 0.272 & 0.563 & 0.811 \\
\hline $\begin{array}{l}\text { Canton FE } \\
\text { Year FE }\end{array}$ & & $\checkmark$ & $\checkmark$ & $\begin{array}{l}\checkmark \\
\checkmark\end{array}$ \\
\hline
\end{tabular}

Note: The table shows placebo OLS regression estimates. The dependent variable is canton-level turnout in referendums. Standard errors are clustered by referendum day. 
Table A.2: The Effect of Postal Voting on Turnout in Referendums, 1981-2009 (Probit Models)

\begin{tabular}{lccc}
\hline & \multicolumn{3}{c}{ Survey Data } \\
\cline { 2 - 4 } & $(1)$ & $(2)$ & $(3)$ \\
\hline Postal Voting & 0.046 & 0.050 & 0.046 \\
& $(0.014)$ & $(0.011)$ & $(0.011)$ \\
\hline Observations & 78,464 & 73,443 & 69,116 \\
R-squared & 0.01 & 0.04 & 0.10 \\
\hline Controls & & & $\checkmark$ \\
Canton FE & & $\checkmark$ & $\checkmark$ \\
Year FE & & $\mathbb{V}$ & $\checkmark$ \\
\hline
\end{tabular}

Note: The table shows the marginal effects of postal voting based on three separate probit regressions using postreferendum survey data. The control variables (controls) are: Age, education, adn religious denomination. The appendix provides a detailed description of all variables. Standard errors are clustered by referendum day. 